\title{
Optimum Portföy Oluşturma: BIST Kurumsal Yönetim Endeksi (XKURY) Üzerine Bir Uygulama
}

\author{
Gülce Pırıl BAŞAR*, Özlem KUVAT**
}

ÖZ

Finansal piyasalar, geniş bir yelpazeye sahip yatırım enstrümanlarını barındırdığından yatırımcılar çok çeşitli yatırım araçlarıyla karşı karşıya kalmaktadırlar. Yatııımcılar bu yatırım araçları arasından en büyük faydayı sağlayacak optimum portföy oluşturma çabası içindedirler. Bu çalışmada, finans alanında modern portföy kuramının başlangıcı kabul edilen Markowitz Ortalama Varyans metodu kullanılıp, BİST Kurumsal Yönetim Endeksinde (XKURY) yer alan hisse senetlerinin 2009-2018 yılları arasındaki aylık kapanış fiyatlarından hareketle modelleme yapılmış ve portföy optimizasyonu uygulamasıyla optimum portföyler oluşturularak gerçekleşen sonuçların beklenen sonuçlarla uyum içinde olduğu saptanmıştır. Ayrıca Sharpe oranları ve değişim katsayıları da dikkate alınarak Ortalama Varyans Modeli ile en yüksek getirili ve eşit ağıllıklı 6 hisse senedi seçimine dayalı EYG6HS modeli ile oluşturulan portföylerin, kıyaslaması yapılmıştır. Karşılaştırma sonucunda Ortalama Varyans modelinin geçerliliğini destekleyen sonuçlar elde edilmiştir.

Anahtar Kelimeler: Portföy Optimizasyonu, Optimum Portföy, Ortalama Varyans Modeli, Kurumsal Yönetim Endeksi

JEL Sinıflandırması: G11, C61, G32

\section{Optimum Portfolio Creation: BIST Corporate Governance Index (XKURY) Application}

\begin{abstract}
As financial markets have a wide range of investment instruments, investors face a wide range of investment instruments. Investors are in the effort to create an optimum portfolio that will provide them with the highest level of benefit among all these investment instruments. In this study, Markowitz Mean Variance method, which is accepted as the beginning of modern portfolio theory in finance field, was used respectively. In the BIST Corporate Governance Index (XKURY), it was modeled on the monthly closing prices of the stocks in 2009-2018. Sharpe ratios and coefficients of variation are also included in the application. The portfolios created with Mean Variance Model were compared with EYG6HS model based on 6 stocks with the highest yield and equal weight. As a result of the comparison, the results supporting the validity of the Mean Variance Model were obtained.
\end{abstract}

Keywords: Portfolio Optimization, Optimum Portfolio, Mean Variance Model, Corporate Governance Index

JEL Classification: G11, C61, G32

Geliş Tarihi / Received: 17.04.2019 Kabul Tarihi / Accepted: 03.11.2019

\footnotetext{
* Balıkesir Üniversitesi, Sosyal Bilimler Enstitüsü, gulcebasar23@hotmail.com, ORCID: 0000-0002-6490-0732.

** Dr. Öğr. Üyesi, Balıkesir Üniversitesi, İ̈BF, İşletme Bölümü, ohasgul@balikesir.edu.tr, ORCID: 0000-0001-70174557.
} 


\section{GİRIŞ}

Bireyler tasarruflarını, geleceğe yönelik belirsizliklerin yol açabileceği olumsuz etkilerden korumak için çeşitli yatırım araçlarına yönlendirmeyi tercih ederler. $\mathrm{Bu}$ yatırım araçları hazine bonosu, devlet tahvili, banka faizi ve repo gibi risksiz yatırım araçları olabileceği gibi hisse senedi ve döviz gibi riskli yatırım araçları da olabilir. Yatırımcının parasını ne yönde değerlendirmesi gerektiği konusunda yaşadığı belirsizlik önemli bir sorun oluşturmaktadır. $\mathrm{Bu}$ durum finansal varlıkların seçimi ve yönetiminin detaylı bir şekilde ele alınmasını beraberinde getirmiştir.

Son yıllarda dünyada oluşan siyasi ve ekonomik dalgalanmalar, uluslararası iktisadi faaliyetlerin hız kazanmasına neden olmuştur. Buna bağlı olarak, sermaye piyasasına yeni finansal enstrümanlar dâhil olmuş ve borsada işlem görmeye başlayan firmaların sayılarında artış meydana gelmiştir. Böyle bir ortamda, yatırımcılar tasarruflarının büyük bir kısmını, söz konusu yatırım araçlarına yönlendirmişlerdir. Finansal varlıkların çeşitliliğinin artması, birden fazla finansal varlığa yatırım yapmanın riski minimize edeceği düşüncesini doğurmakla birlikte portföy ve portföy optimizasyonu kavramının temellerini oluşturmuştur. Portföy optimizasyonu; minimum risk ve maksimum getiri elde edebilmek amacıyla belli kısıtlar dâhilinde portföye dâhil edilecek finansal varlıkların oransal dağılımlarının hesaplanmasını sağlayan matematiksel bir modeldir.

Yatırımcıların optimum portföye ulaşabilmeleri için en doğru kararı verebilmeleri açısından birçok portföy yönetim tekniği geliştirilmiştir. Bu çalışmada ise Modern Portföy Teorisinin kurucusu olan Harry Markowitz' in Ortalama-Varyans modeli (OVM) ele alınmıştır. Çalı̧̧mada OVM'nin BIST Kurumsal Yönetim Endeksi (XKURY) 2016-2018 verileri için de optimal portföy elde edilmesindeki önemini ortaya koymak hedeflenmiştir.

Kurumsal yönetimin tüm işletmeler için giderek önem kazanması ile kurumsal yönetimin belirli kriterler şeklinde düzenlenmesi için kurumsal yönetim ilkeleri 1999'da OECD, 2003 'te Sermaye Piyasası Kurulu tarafindan yayınlanmıştır. SPK tarafindan yayınlanan kriterlere göre; kurumsal yönetim ilkelerine uyum göstermekte olan şirketlerin fiyat ile getiri performanslarını ölçmek amacıyla Türkiye'de 31 Ağustos 2007'de BIST Kurumsal Yönetim Endeksi (XKURY) hesaplanmaktadır. Bu Endeks "Kurumsal Yönetim İlkeleri”ni uygulayan ve ayrıca kurumsal yönetim notu alan halka açık olan şirketlerin hisse senetlerinin işlem gördüğü bir endekstir. Amacı, payları Borsa İstanbul pazarlarında (Gözaltı Pazarı ve C Listesi hariç olarak) işlem görmekte olan ve kurumsal yönetim ilkelerine uyum notu 10 üzerinden en düşük 7 ve her bir ana başlık itibarıyla 10 üzerinden en düşük 6,5 olan şirketlerin fiyat ile getiri performansının ölçülmesidir (Doğrusoy, 2014: 33; Aksu ve Aytekin, 2015: 202).

Çalışma toplam dört bölümden oluşmaktadır. Giriş bölümünü takiben, çalışmanın ikinci bölümünde; Markowitz Ortalama-Varyans modeline ilişkin bilgiler verilmiş ve literatürde yer alan çalışmalara değinilmiştir. Üçüncü bölümde, Markowitz'in Ortalama Varyans modeli kullanılarak BIST Kurumsal Yönetim Endeksinde yer alan hisse senetlerinden oluşan optimum portföy oluşturma ile ilgili bir uygulama yapılmıştır. 2009-2018 yılları arasındaki hedeflenen getiriler dikkate alınarak etkin sınır eğrileri çizilmiş, Sharpe oranları ve değişim katsayıları hesaplanmıştır. Ayrıca, 34 adet hisse senedi içerisinden en yüksek getiriye sahip 6 hisse senedinin dahil edilmesiyle oluşturulan portföylerin performansları ölçülmüş̧ ve Ortalama Varyans Yöntemine göre oluşturulan portföylerin performanslarıyla karşılaştırılmıştır. OVM ile oluşturulan portföylerin daha yüksek performansa sahip olduğu saptanmıştır. Çalışmanın son bölümünde ise uygulama kapsamında elde edilen sonuçlara değinilmiştir. 


\section{PORTFÖY OPTIMIZASYONU}

\subsection{Modern (Markowitz) Portföy Teorisi}

Harry Markowitz'in 1952 yılında yayınlamış olduğu ve daha sonra kitap haline dönüştürdügü (1959) "Portföy Seçimi” adlı Nobel ödüllü makalesiyle modern portföy teorisinin temelleri atılmıştır. Markowitz modelinin temel amacı beklenen getiri düzeyine ulaşabilmek için minimum riske sahip portföyü oluşturabilmek ve böylelikle portföy optimizasyonunu sağlamaktır (Markowitz, 1952; Ulucan, 2004: 1-2). Tek fikirli yüksek getiri arayışı, zayıf bir strateji oluşturur. Çünkü rasyonel yatırımcılar yüksek getiriyi düşük riskle elde etmek isterler. $\mathrm{Bu}$ teoriye göre yatırımcılar portföylerini oluştururken uygun risk ve getiri firsatlarını değerlendirirler. Bu da riskli varlığın minimum varyanslı sınırı olarak özetlenmektedir (Brodie vd., 2009: 12267; Bodie, Kane ve Marcus, 2002: 223).

Ortalama Varyans modeli olarak ta adlandırılan teoriye göre; sabit varyans ile beklenen getiriyi en yüksek düzeye çıkarma ve beklenen getiriyi sabit tutarak varyansı en aza indirmeye dayanan iki temel ilke bulunmaktadır. Bu şekilde yatırımcının bireysel risk getiri tercihlerine dayanan portföylerden oluşan seçim yapmaya uygun olan etkin bir sınırın oluşturulması sağlanmaktadır (Elton ve Gruber, 1997: 1744). Global minimum varyansa göre minimum varyans sınırında yer alan ve yukarı yönlü tüm portföyler, en iyi risk-getiri kombinasyonlarını sağlar ve dolayısıyla en uygun portföy için adaydırlar. Sınırın, global minimum değişkenlik portföyünün üzerinde kalan kısmına, riskli varlığın etkin sınırı denmektedir (Bodie, Kane ve Marcus, 2002: 225).

Markowitz'in en önemli katkılarından biri kişisel menkul kıymetin riskliliği ile tüm portföyün risklilik oranlarının birbirinden ayırmasıdır. Bir portföyün riskliliği yatırımların ayrı ayrı risk oranlarına değil; portföyün içindeki menkul kıymetlerin kovaryansına bağlıdır. Buna göre; oluşturulan portföyler arasında bazıları daha etkindir. Bir portföy, verilen bir risk seviyesi için en yüksek getiriyi ve belirli bir getiri seviyesi için en düşük riske sahipse etkindir. Belli bir risk seviyesi için daha fazla getiri ya da belirli bir getiri seviyesi için daha az risk varsa, bir portföy diğerine hakim olmaktadır. Etkin portföy; aynı risk değerine sahip olan portföylerden getirisi yüksek olan ya da aynı getiri değerine sahip portföylerden düşük riski olandır (Doğukanlı ve Borak, 2018: 42; Pringle Jr ve VanOrden, 2009: 9). Etkin yani Pareto-optimal portföylerin önemli bir yönü de her birinin, yatırım getirisinin beklenen faydasını maksimize ettiği bir fayda fonksiyonunu belirlemesidir. Bu durum Markowitz'in yaklaşımını belirsizlik altındaki rasyonel davranış teorisi ile yorumlamasını sağlamıştır (Steinbach, 2001: 31). Etkin bir portföy ortalama portföy primi getirisine ve ilave kısıtlamalara (riskli varlıklardaki yatırım oranlarının toplamının bir olması gibi) tabi olarak portföy varyansını en aza indirerek belirlenir (Jobson ve Korkie, 1980: 544).

Markowitz'in geliştirdiği modelde iki temel kısıt bulunmaktadır. Ancak modelin son hali üçüncü bir kısıtın modelde yer almasıyla elde edilmiştir. Bu kısıtlardan ilki, portföyden sağlanan getirinin yatırımcının hedeflediği getiri seviyesine ulaşmasıdır. İkinci kısıt ise, portföy içerisinde yer alan varlıkların toplam ağırlık değerinin 1'e eşit olmasıdır. Son olarak her bir varlığın portföy içerisindeki ağırlı̆̆ını temsil eden karar değişkenlerinin negatif olamama kısıtı da ilave edildiğinde genel model elde edilmektedir. Burada, $n$ : menkul değer sayısı, $\sigma_{i j}: i$ ve $j$ varlıkları arasındaki kovaryans değeri, $w_{i}, w_{j}$ : karar değişkenleri, $\mu_{i}: i$. varlığının beklenen getirisi, $R$ : hedeflenen getiri düzeyidir (Markowitz, 1952: 83; Ulucan, 2004: 17-18): 
Min. $\quad \sum_{i=1}^{n} \sum_{j=1}^{n} w_{i} w_{j} \sigma_{i j}$

k.a.

$\sum_{i=1}^{n} w_{i} \mu_{i} \geq R$
$\sum_{i=1}^{n} w_{i}=1$
ve $0 \leq w_{i} \leq 1$

\subsection{Optimum Portföy Oluşturma Konusunda Literatür Taraması}

Modern anlamda Markowitz tarafından portföy çeşitlenmesinin önerilmesinin ardından literatürde portföy optimizasyonu konusunda pek çok çalışma ile katkılar sağlanmıştır. Bunların bir k1smı Mokhtar, M., Shuib, A., \& Mohamad, D. (2014), Metaxiotis, K., \& Liagkouras, K. (2012), Zhang, Y., Li, X., \& Guo, S. (2018) tarafından yapılan çalışmalarda düzenlenerek sunulmaktadır. Türkiye'de yapılan çalışmalara örnekler de aşağıda verilen tabloda verilmektedir.

Tablo 1: Türkiye'de Yapılan Çalışmalara Örnekler

\begin{tabular}{|c|c|c|c|c|}
\hline Yazar & Yil & Tarih & Endeks & Model ve Sonuçları \\
\hline 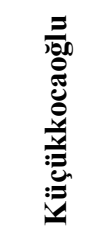 & 2002 & $\begin{array}{l}\text { 04/01/1999 } \\
- \\
\text { 28/12/1999 } \\
\text { günlük }\end{array}$ & $\begin{array}{l}\text { İMKB Ulusal-30 } \\
\text { İMKB Ulusal-100 }\end{array}$ & $\begin{array}{l}\text { OVM kullanılmıştır. Çalışma sonucunda optimize edilmiş } \\
\text { etkin portföyün oluşturulduğu kanısına varılmıştır. }\end{array}$ \\
\hline$\stackrel{\pi}{\pi}$ & 2005 & $\begin{array}{l}\text { Ocak } 2003- \\
\text { Aralık } 2004 \\
\text { haftalık }\end{array}$ & İMKB 100 & $\begin{array}{l}\text { OVM ile eşit getiri seviyesinde daha düşük risk içeren } \\
\text { portföy ağırlıkları saptanarak yatırımcıların risk algılama } \\
\text { düzeylerine göre alternatifler oluşturulmuştur. }\end{array}$ \\
\hline 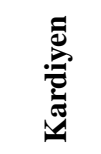 & 2007 & $\begin{array}{l}\text { Ocak } 2000- \\
\text { Aralık } 2004\end{array}$ & İMKB-100 & $\begin{array}{l}10 \text { tane hisse senedi seçerek elde ettiği veriler için ortalama } \\
\text { mutlak sapma modelini kullanmıştır. }\end{array}$ \\
\hline : & 2008 & $\begin{array}{l}1 \text { Ocak } 2004 \\
\text { ile } 31 \text { May1s } \\
2007 \text { aylik }\end{array}$ & $\begin{array}{l}\text { İMKB Mali } \\
\text { Sektörü } 65 \text { şirkete } \\
\text { ait hisse senetleri }\end{array}$ & $\begin{array}{l}\text { Konno-Yamazaki Modeli kullanılmıştır. OVM gibi K-Y } \\
\text { Modeli ile de yatırımcılar katlanmak istedikleri risk düzeyi } \\
\text { doğrultusunda kendi portföylerini oluşturabilir. }\end{array}$ \\
\hline 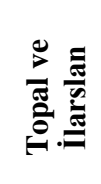 & 2009 & $\begin{array}{l}\text { 02/01/2006 - } \\
\text { 29/12/2006 } \\
\text { günlük }\end{array}$ & İMKB-30 & $\begin{array}{l}\text { OVM ile oransal dağılımları eşit olan menkul kıymetlerden } \\
\text { oluşan bir portföy meydana gelmiştir. Bu portföyün etkin } \\
\text { sınır ile risksiz getiri oranı arasındaki ilişkisi geometrik } \\
\text { açıdan incelenmiştir. Optimal portföyün bir Tanjant } \\
\text { portföyü olduğu tespit edilmiştir. }\end{array}$ \\
\hline
\end{tabular}




\begin{tabular}{|c|c|c|c|c|}
\hline 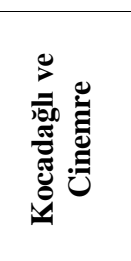 & 2010 & $\begin{array}{l}\text { Nisan } 2008 \\
42 \text { seans }\end{array}$ & $\begin{array}{l}\text { İMKB30 işlem } \\
\text { gören } 30 \text { hisse } \\
\text { senedinin }\end{array}$ & $\begin{array}{l}\text { Bulanık doğrusal olmayan matematiksel programlama } \\
\text { yaklaşımı kullanılmıştır. Öncelikle minimum ve maksimum } \\
\text { risk değerleri bulunmuş ve elde edilen bu risk aralığı } \\
\text { yardımıyla riske ait üyelik fonksiyonu oluşturulmuştur. } \\
\text { Daha sonra beklenen getiri, risk ve portföy betasının üyelik } \\
\text { fonksiyonları birlikte değerlendirilerek en iyi portföy elde } \\
\text { edilmiștir. }\end{array}$ \\
\hline 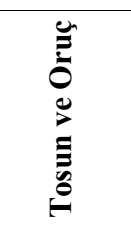 & 2010 & $\begin{array}{l}\text { Ocak-2001 } \\
\text { ve Aralik- } \\
\quad 2008\end{array}$ & $\begin{array}{l}\text { İMKB-30 } \\
\text { Endeksinde } \\
\text { sürekli işlem } \\
\text { gören } 20 \text { adet } \\
\text { hisse senedi }\end{array}$ & $\begin{array}{l}\text { OVM kullanılarak, yatııımcının en düşük risk ve en yüksek } \\
\text { getiri ilişskisine dayalı beklentisini karşılayacak en uygun } \\
\text { hisse senedi sayısına ait bir portföy oluşturulmuştur. } \\
\text { Çalışmanın sonucunda } 6 \text { adet hisse senedinden oluşacak bir } \\
\text { portfoyün yatırımcı açısından yeterli çeşitlendirmeye sahip } \\
\text { olduğu düşünülmektedir. }\end{array}$ \\
\hline 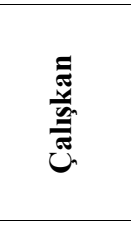 & 2011 & $\begin{array}{l}\text { 02/01/2003- } \\
\text { 30/06/2009 } \\
\text { günlük }\end{array}$ & $\begin{array}{l}\text { İMKB-30 } \\
\text { Endeksinde işlem } \\
\text { gören } 17 \text { şirkete } \\
\text { ait hisse senetleri }\end{array}$ & $\begin{array}{l}\text { OVM ve Black Litterman Modeli kullanılarak } 13 \text { portföy } \\
\text { oluşturulup portföylerin performansları Sharpe, Treynor ve } \\
\text { Jensen performans ölçütleri kullanılarak ölçülüp } \\
\text { karşlaştırılması yapılmıştır. En yüksek performansa sahip } \\
\text { olan portföylerin Black Litterman Modeliyle oluşturulan } \\
\text { portföyler olduğu saptanmıştır. }\end{array}$ \\
\hline 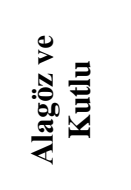 & 2012 & $\begin{array}{l}2000 \text { ile } \\
2009 \text { yılları } \\
\text { arasındaki } \\
\text { y1llik } \\
\text { getirileri }\end{array}$ & Emtia piyasası & $\begin{array}{l}\text { Parçacık Sürü Optimizasyon (PSO) tekniği ile elde ettikleri } \\
\text { sonuçları OVM ile karşılaştırmışlardır. Her iki yöntem ile } \\
\text { beklenen getiri, risk ve ürünlerin portföy içerisindeki } \\
\text { ağırlıkları hesaplanarak karşılaştırma yapılmış ve birbirine } \\
\text { yakın sonuçların çıktığı saptanmıştır. }\end{array}$ \\
\hline 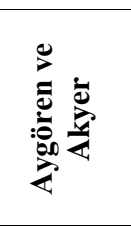 & 2013 & $\begin{array}{l}\text { 01 Nisan } \\
1994-15 \\
\text { Mayis } 2011 \\
\text { günlük, } \\
\text { haftalık ve } \\
\text { aylık }\end{array}$ & $\begin{array}{l}\text { BIST-30'da işlem } \\
\text { gören } 5 \text { ve } 9 \text { adet } \\
\text { hisse senedi }\end{array}$ & $\begin{array}{l}\text { OVM ve Ki-kare test istatistiği kavramı çalışmanın } \\
\text { metodunu oluşturmuştur. Portföy veri-aralığı, portföydeki } \\
\text { hisse senetleri sayısı ve risk faktörü ele alınmıştır. Düşük ve } \\
\text { orta risk seviyelerinde oluşan portföylerin homojen yapıda } \\
\text { olduğu gözlemlenerek günlük ya da haftalık verilerin } \\
\text { kullanılması önerilmiştir. }\end{array}$ \\
\hline$\stackrel{\overparen{E}}{\gtrless}$ & 2013 & $\begin{array}{l}2005 \text { yilına } \\
\text { ait } 12 \text { aylık } \\
\text { getiri }\end{array}$ & İMKB 30 & $\begin{array}{l}\text { Kuadratik programlama modeli kullanılarak İMKB } 30 \\
\text { endeksi ile aynı risk - getiri değerlerine sahip portföy tespit } \\
\text { edilmiş ve İMKB30 endeksini oluşturan hisse senetleri ile } \\
\text { aynı getiriye sahip daha düşük riskli portföyler ve aynı riske } \\
\text { sahip daha yüksek getirili portföylere ulaşılmıştır. }\end{array}$ \\
\hline 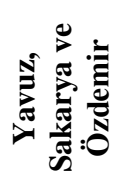 & 2015 & $\begin{array}{l}2010 \text { yılına } \\
\text { ait aylık } \\
\text { ortalama } \\
\text { getirileri }\end{array}$ & $\begin{array}{c}\text { BIST Sinai } \\
\text { Endeksi'nde yer } \\
\text { alan } 140 \text { hisse } \\
\text { senedi }\end{array}$ & $\begin{array}{l}\text { YSA çalışması ile getiri ve risk bazında en iyi sonucu } \\
\text { özsermayeye göre oluşturulan portföylerden elde } \\
\text { etmişlerdir. Yapay sinir ağları ile getiri tahminini \%1'in } \\
\text { altında hata oranı ile gerçekleştirmişler, risk tahmininde ise } \\
\text { \%0.5'in altında hata ile tahmin yapmışlardır. }\end{array}$ \\
\hline 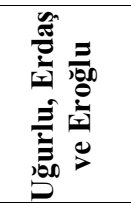 & 2016 & $\begin{array}{l}\text { Ocak } 2009 \\
\text { ve Mart } \\
2010\end{array}$ & $\begin{array}{l}\text { BIST } 10083 \\
\text { işletme }\end{array}$ & $\begin{array}{l}\text { Büyüt boyutlu portföyleri optimize etmek için Konno } \\
\text { Yamazaki Doğrusal programlama modeli kullanılmıştır. }\end{array}$ \\
\hline 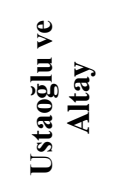 & 2017 & $2000-2015$ & $\begin{array}{c}\text { BIST-100 } \\
\text { Endeksinde işlem } \\
\text { gören } 59 \text { hisse } \\
\text { senedi }\end{array}$ & $\begin{array}{l}\text { Stokastik Portföy Teorisine dayalı log-optimal portföyler } \\
\text { ile OVM göre oluşturulan portföylerin uzun dönem } \\
\text { performansları karş1laştırılmıştır. } 32 \text { ölçümden } 29 \text { tanesinde } \\
\text { log-optimal portföylerin OVM ile oluşturulan portföylere } \\
\text { göre daha yüksek performans gösterdiği saptanmıştır. }\end{array}$ \\
\hline 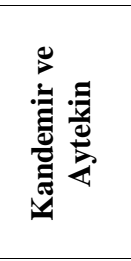 & 2017 & $\begin{array}{c}01.01 .2009 \\
31.12 .2014\end{array}$ & $\begin{array}{c}\text { BIST Sanayi } \\
\text { Endeksinde kote } \\
\text { edilen } 45 \text { firmaya } \\
\text { ait hisse senetleri }\end{array}$ & $\begin{array}{l}\text { OVM kullanarak oluşturulan portföyler arasından sharpe } \\
\text { performans kriteri kullanılarak optimum portföylere } \\
\text { ulaşılmıştır. Ayrıca eşit ağırlıkta yatırım yapılarak } \\
\text { oluşturulan portföylerin sharpe oranları OVM ile } \\
\text { oluşturulan optimum portföylerin Sharpe oranları ile } \\
\text { mukayese edilmiş ve OVM kapsamında oluşturulan } \\
\text { portföylerin daha başarılı sonuçlar verdiği gözlemlenmiştir. }\end{array}$ \\
\hline
\end{tabular}




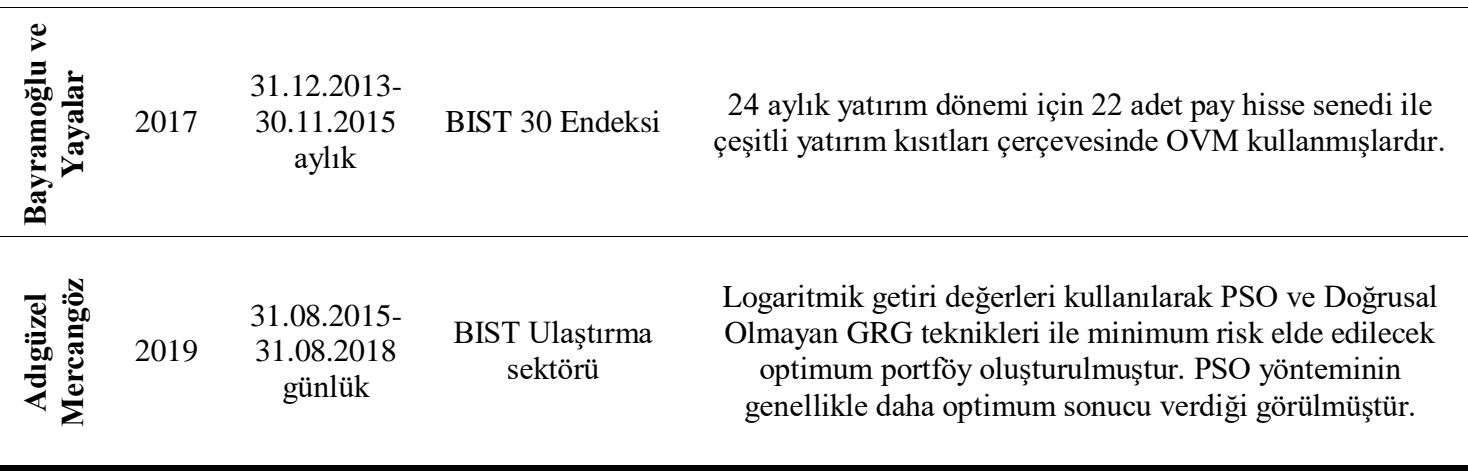

Literatürde yer alan çalışmalara göre OVM'nin oluşturulan farklı portföyler için başarılı sonuçlar verdiği görülmüştür. OVM'nin çözümlemede sıkıntılı olabileceği büyük boyutlardaki portföylerin optimizasyonu için KY, Black Litterman Modelleri, log-optimal portföyler, bulanık programlama ve yapay zeka... gibi teknikler de etkin sonuçlar sunmaktadır. Bu çalışmada ele alınan veri seti dikkate alındığında literatürdeki sonuçlara da dayanarak OVM yöntemi problem için uygun bir yöntem olarak değerlendirilmiştir.

\section{BIST KURUMSAL YÖNETIM ENDEKSİ ÜZERINNE PORTFÖY OPTIMIZASYONU UYGULAMASI}

\subsection{Uygulamanın Amacı}

$\mathrm{Bu}$ çalışmanın amacı, Markowitz'in Ortalama Varyans modeli esas alınarak BIST Kurumsal Yönetim Endeksinde (XKURY), işlem gören firmalara ait hisse senetlerinden oluşan portföyler oluşturmak ve sharpe performans ölçütü ile değişim katsayısını kullanılarak bu portföyler içerisinden risk-getiri ilişkisi kapsamında optimal portföyü elde etmektir. BIST Kurumsal Yönetim Endeksi Kurumsal Yönetim İlkeleri'ni uygulayan şirketlerin dâhil edildiği endekstir. Yatırımcılar günümüzde seçim yaparken iyi kurumsal yönetim, daha iyi faaliyet yönetimi, daha iyi piyasa değeri ve daha fazla geri dönüşüm gibi kavramları dikkate alarak kurumsal yönetim uygulamalarını daha büyük oranda önemsemektedirler. Endeks, yatırımcıların kurumsal yönetim ilkelerini başarıyla uygulayabilen şirketleri tanınmasını ve takdir etmesini kolaylaştıracak bir mekanizma oluşturacaktır (Sakarya, 2011: 148). Bu çalışmada kurumsal yönetim ilkelerine uyumu başarabilen şirketlerin rekabet avantajına sahip olan ve risk düzeyleri düşük şirketler oldukları varsayımıyla portföy optimizasyonu için özellikle incelenmesi gerektiği kanısına varılmıştır.

\subsection{Uygulamada Kullanılan Veri Seti}

Çalışmada veri seti olarak Ocak-2009 ve Aralık-2018 tarihleri arasında BIST Kurumsal Yönetim Endeksinde işlem gören 34 adet hisse senedinin aylık kapanış değerleri kullanılmıştır. Veri seti olarak 2018 yılı Ağustos ayı itibarıyla Kurumsal Yönetim Endeksinde yer alan firmaların geçmişe dönük verisinden oluşmaktadır. Çalışmanın ilk aşamasında modelin çözümünün 51 firma üzerinde uygulanmaya çalışılması düşünülmüş ancak finansal kuruluşlara ait hisse senetlerinin ağırlık bakımından yapısının homojen olmaması ve PEGASUS'a ait verilere ulaşılamaması nedeniyle modele dâhil edilen hisse senedi sayısında düşüş yaşanmıştır. Mevcut veriler, Financial Information News Network (FINNET) Analiz Expert veri tabanından (https://www.finnet.com.tr/) akademik çalışma amacıyla sağlanmıştır. İlgili dönem için ele alınan Şirketler ve getirilere ilişkin betimsel istatistik bilgileri aşağıda verilen tabloda sunulmaktadir. 
Tablo 2: Çalışma Kapsamına Alınan Şirketler

\begin{tabular}{|c|c|c|c|c|c|c|}
\hline Kod & Ad & $\begin{array}{l}\text { Ortalama } \\
\text { Getiri }\end{array}$ & $\begin{array}{c}\text { Standart } \\
\text { Sapma }\end{array}$ & Enküçük & Enbüyük & $\begin{array}{l}\text { Değişim } \\
\text { Aralığı }\end{array}$ \\
\hline AKSA & AKSA & 0,0345 & 2,88 & $-0,44$ & 1,05 & 1,49 \\
\hline AEFES & ANADOLU EFES & 0,0087 & 0,15 & $-0,24$ & 0,42 & 0,66 \\
\hline AGHOL & $\begin{array}{c}\text { ANADOLU GRUBU } \\
\text { HOLDING }\end{array}$ & 0,0109 & 0,10 & $-0,16$ & 0,25 & 0,41 \\
\hline ARCLK & ARÇELIK & 0,018 & 0,08 & $-0,34$ & 0,46 & 0,8 \\
\hline ASELS & ASELSAN & 0,0387 & 0,11 & $-0,73$ & 2,76 & 3,49 \\
\hline AYGAZ & AYGAZ & 0,0296 & 0,27 & $-0,28$ & 0,37 & 0,65 \\
\hline CCOLA & COCA COLA İÇECEK & 0,0792 & 0,11 & $-0,84$ & 5,42 & 6,26 \\
\hline DOHOL & DOĞAN HOLDİNG & 0,0271 & 0,51 & $-0,5$ & 1,06 & 1,56 \\
\hline DGGYO & DOĞUȘ GMYO & 0,0214 & 0,14 & $-0,35$ & 0,53 & 0,88 \\
\hline DOAS & DOĞUŞ OTOMOTIV & 0,0226 & 0,11 & $-0,27$ & 0,37 & 0,64 \\
\hline ENKAI & ENKA İNŞAAT & 0,0155 & 0,10 & $-0,25$ & 0,7 & 0,95 \\
\hline EREGL & EREĞLİ DEMIR ÇELIK & 0,0212 & 0,13 & $-0,24$ & 1,07 & 1,31 \\
\hline GLYHO & $\begin{array}{l}\text { GLOBAL YATIRIM } \\
\text { HOLDING }\end{array}$ & 0,0267 & 0,15 & $-0,29$ & 0,44 & 0,73 \\
\hline HURGZ & HÜRRIYET GAZETESİ & 0,019 & 0,12 & $-0,36$ & 0,76 & 1,12 \\
\hline IHEVA & İHLAS EV ALETLERİ & 0,0828 & 0,12 & $-0,85$ & 7,68 & 8,53 \\
\hline IHLAS & İHLAS HOLDİNG & 0,0175 & 0,71 & $-0,16$ & 0,43 & 0,59 \\
\hline IZOCM & IZOCAM & 0,0272 & 0,10 & $-0,47$ & 1,25 & 1,72 \\
\hline LOGO & LOGO YAZILIM & 0,0123 & 0,18 & $-0,27$ & 0,26 & 0,53 \\
\hline MGROS & MİGROS TİCARET & 0,0263 & 0,08 & $-0,54$ & 1,03 & 1,57 \\
\hline OTKAR & OTOKAR & 0,0158 & 0,16 & $-0,28$ & 0,47 & 0,75 \\
\hline PRKME & $\begin{array}{l}\text { PARK ELEKTRIK } \\
\text { MADENCILIK }\end{array}$ & 0,0112 & 0,14 & $-0,35$ & 0,61 & 0,96 \\
\hline PETUN & PINAR ET VE UN & 0,0217 & 0,15 & $-0,58$ & 1,2 & 1,78 \\
\hline PINSU & PINAR SU & 0,0172 & 0,19 & $-0,24$ & 0,33 & 0,57 \\
\hline PNSUT & PINAR SÜT & 0,0367 & 0,09 & $-0,66$ & 1,84 & 2,5 \\
\hline SISE & ŞIŞE CAM & 0,0135 & 0,20 & $-0,23$ & 0,48 & 0,71 \\
\hline TATGD & TAT GIDA & 0,0903 & 0,11 & $-0,87$ & 6,53 & 7,4 \\
\hline TAVHL & TAV HAVA LIMAANLARI & 0,0151 & 0,62 & $-0,3$ & 0,59 & 0,89 \\
\hline TOASO & $\begin{array}{l}\text { TOFAŞ OTOMOBIL } \\
\text { FABRIKASI }\end{array}$ & 0,0348 & 0,12 & $-0,38$ & 0,56 & 0,94 \\
\hline TUPRS & TÜPRAŞ & 0,0153 & 0,13 & $-0,29$ & 0,49 & 0,78 \\
\hline TRCAS & TURCAS PETROL & 0,019 & 0,12 & $-0,23$ & 0,25 & 0,48 \\
\hline PRKAB & TÜRK PRYSMİAN KABLO & 0,0045 & 0,08 & $-0,25$ & 0,38 & 0,63 \\
\hline TTKOM & TÜRK TELEKOM & 0,0182 & 0,09 & $-0,33$ & 0,67 & 1 \\
\hline TTRAK & TÜRK TRAKTÖR & 0,0142 & 0,11 & $-0,36$ & 0,53 & 0,89 \\
\hline VESTL & VESTEL & 0,0448 & 0,12 & $-0,71$ & 2,41 & 3,12 \\
\hline
\end{tabular}


Ortalama Getiri değerlerine göre; ilgili dönem için en yüksek getiriye sahip hisse senetleri TATGD, IHEVA, CCOLA, VESTL, ASELS olmuştur. En düşük değişkenliğe sahip hisseler ise; standart sapmaya göre AGHOL LOGO TRCAS PRKAB PINSU, değişim aralığına göre AGHOL TRCAS LOGO PINSU IHLAS şeklinde sıralanmıştır.

Çalışma kapsamında kullanılan bir diğer veri seti de Sharpe oranının hesaplanabilmesi için ihtiyaç duyulan risksiz faiz oranlarıdır. Bu faiz oranlarının hesaplanmasında, TCMB'nin internet sitesinde ilgili yıllar için yayınladığı ihracı yapılan kısa vadeli devlet iç borçlanma senetlerinin yıllık ortalama basit faiz oranları kullanılmıştır.

Tablo 3: 2009-2018 Y1lları Arasındaki Risksiz Faiz Oranları

\begin{tabular}{cccc}
\hline Yıl & Oran $(\%)$ & Yll & Oran $(\%)$ \\
\hline 2009 & 11,53 & 2014 & 8,81 \\
\hline 2010 & 7,52 & 2015 & 9,58 \\
\hline 2011 & 8,12 & 2016 & 9,97 \\
\hline 2012 & 7,65 & 2017 & 11,61 \\
\hline 2013 & 8,88 & 2018 & 18,77 \\
\hline
\end{tabular}

Kaynak: TCMB (21 Kasım 2018),

http://www.tcmb.gov.tr/wps/wcm/connect/TR/TCMB+TR/Main+Menu/IstatistiklerPiyasa+Verileri/ihale+Yontemi+il e+Satilan+Hazine+Bonolari+ve+Devlet+Tahvilleri/

\subsection{Uygulamada Kullanılan Model ve Aşamaları}

Markowitz Modeli’ne göre yatırımcıların, mevcut yatırım alternatifleri arasından aynı riske sahip ancak farklı getiriyi sağlayan portföyü tercih edip optimum portföy oluşturabilmeleri için bazı bilgilere ihtiyaç duyulmaktadır. Bunlar; portföye dahil edilecek her bir menkul kıymetin beklenen getirisinin hesaplanarak yatırım karlılığının ölçülmesi, her bir menkul kıymetin risk ölçüsü olan varyans veya standart sapmanın hesaplanması, portföy kapsamına alınacak menkul kıymetlerin aralarındaki korelasyon katsayısının veya kovaryansının hesaplanması şeklindedir (Birgili ve Tuna, 2010: 2).

$\mathrm{Bu}$ değerlerin hesaplanması için uygulamada öncelikli olarak Hisse senetlerinin 20092018 yıllarına ait aylık kapanış verilerinden yararlanarak dönemlik beklenen getiri ve ortalama getirilerinin hesaplanması sağlanmıştır. Ortalama Varyans modeli ile farklı beklenen getiri düzeyleri için optimal olan portföyler elde edilmiştir. Daha sonra; hedeflenen getiri düzeyleri ile ilgili getiri düzeyinde elde edilen optimal ve etkin portföylerin oluşturduğu etkin sınır eğrisinin çizimi ve yorumlanması sağlanmış, hesaplanan sharpe oranları ve değişim katsayıları sonucunda her bir yıl için en uygun portföyler önerilmiştir. Sonrasında; ilgili yıllar için en yüksek hedeflenen getiriye sahip 6 hisse senedi seçilip portföyler oluşturulmuş (EYG6HS) ve OVM ile kıyaslanabilmesi için iki hesaplama yönteminin sonuçlarının karşılaştırılması yapılmıştır.

Çalışmada uygulamada veri olarak kullanılan her bir yıl için modelin çözümü ayrı ayrı yapılmıştır. İlk aşamada Markowitz'in Kuadratik (Karesel) Programlama Tabanlı Ortalama Varyans yöntemi esas alınmış ve optimum portföyün seçimine yönelik modelin çözümü gerçekleştirilmiştir. Optimizasyon işlemi için "Microsof Excel 2013" çözücü parametresinde tanımlı "Hedef Ayarla" kısmına modelin amaç fonksiyonu tanımlanmıştır. Burada amaç, portföy riskinin minimize edilmesini sağlamak olduğu için hedef hücresindeki "En Küçük" seçeneği işaretlenmiştir. Karar değişkenleri için "Değişken Hücreleri Değiştirerek" bölümünde varlıkların portföy içerisindeki oranlarının hesaplanması için aralık tanımlanmıştır. Karar değişkenleri ilgili 
hisse senetlerinin kısaltılmış isimleriyle temsil edilmektedir. "Kısıtlamalara Bağlıdır" bölümüne ise modele dâhil edilmiş kısıtlar girilmiştir. Bu kısıtlar; Portföy içerisinde yer alan varlıkların toplam ağırlık değerinin 1'e eşit olması, her bir varlığın portföy içerisindeki ağırlığını temsil eden karar değişkenlerinin negatif olamaması, portföyden sağlanan getirinin yatırımcının hedeflediği getiri seviyesine ulaşması şeklindedir. Tüm bu parametreler tanımlandıktan sonra optimizasyon işlemi gerçekleştirilmiş̧ir (Başar, 2019; Ulucan, 2004: 24; Bodie, Kane ve Marcus, 2002: 231).

\subsection{Yılı İçin Uygulama}

2018 y1lı için farklı beklenen (hedeflenen) getiri düzeylerini karşılayan optimum portföye ulaşabilmek için OVM kullanılmıştır. Etkin sınır eğrisinin çiziminin bu denemelerin ardından farklı getiri düzeylerine sahip her bir portföyün Sharpe oranı ve değişim katsayıları hesaplanmıştır. 20 farklı hedeflenen getiri ve varyans seviyesi için oluşturulan portföylerin içerisinde yer alan değerler, karar değişkenlerinin değerlerini yani yatırım paylarının içermektedir. Portföyler risk getiri yapısını temsil etmekte ve noktalar halinde ekin sınır eğrisini oluşturmaktadırlar. Riski seven yatırımcı eğrinin en sağ tarafında yer alan yüksek riske karşıllık yüksek getiri sağlayan portföyü tercih ederken, riskten uzak durmak isteyen yatırımcı ise eğrinin en sol tarafinda yer alan düşük riske karşl1ık düşük getiri sağlayan portföyü tercih etme eğilimi gösterir.

Portföyler arasından optimum portföye ulaşabilmek için 2018 yılına ait beklenen getiri düzeylerini karşılayan her bir portföyün Sharpe oranı ve değişim katsayıları hesaplamıştır.

Portföyün getirisinin hesaplanmasında, portföydeki bireysel menkul kiymetlerin getirilerinin ağırlıklı ortalaması alınmaktadır. Bu hesaplama aşağıdaki gibi gösterilebilir (Karan, 2013: 139):

$$
\mathrm{E}\left(\mathrm{r}_{\mathrm{p}}\right)=\sum_{\mathrm{j}=1}^{\mathrm{n}} \mathrm{w}_{\mathrm{i}} \cdot \mathrm{E}\left(r_{i}\right)
$$

Formüle göre; $\mathrm{E}\left(r_{p}\right)$ portföy için beklenen getiriyi, $w_{i}$ her bir varlı̆̆ın portföydeki ağırlığını (ağırlık toplamları 1 etmelidir), $\mathrm{E}\left(r_{i}\right)$ her bir varlık için beklenen getiriyi ifade etmektedir (Bodie, Kane ve Marcus, 2002: 221).

Değişim Katsayısı yatırımın ortalama ya da beklenen getirisine göre ne kadar riskli olduğunu gösterir. Standart sapmanın ortalama ya da beklenen getiriye bölünmesiyle bulunur, bir birim getiriye düşen riski göstermektedir. Değişim katsayısı $\partial$ ile gösterilir ve $\sigma_{p}$ portföyün standart sapması iken, aşağıdaki şekilde hesaplanabilir (Doğukanlı ve Borak, 2018: 62):

$$
\partial=\frac{\sigma_{p}}{\mathrm{E}\left(r_{p}\right)}
$$

Sharpe oranı (SR) William F. Sharpe tarafindan 1966 yılında geliştirilen ve standart sapmayı temel alan performans ölçütlerinden biridir. Sharpe oranı, portföyün taşıdığı toplam riske karşılık yatırımcıların talep ettikleri risksiz faiz oranı üzerindeki ek getiriyi göstermektedir. Sharpe, portföyün toplam riskini standart sapma ile ifade etmiştir (Sharpe, 1994: 3; Ayaydın, 2013: 63).

Sharpe oranı ne kadar yüksekse o kadar iyi olarak algılanmaktadır. Çünkü pazarın Sharpe oranından yüksek olması beklenmektedir. Portföy ile risksiz faiz oranını birleştiren doğrunun eğimi şeklinde ifade edilebilir. Yüksek SR değerleri, o alternatifin yüksek performansa sahip olduğunu göstermektedir. Böylece o yatırımın her birim riske (standart sapma yani 
dalgalanırlık) karşılık daha yüksek getiri sağladığı söylenebilir (Aksoy, 2014: 195; Altaylıgil, 2008: 71).

Sharpe oranı, portföyün beklenen getirisi $E\left(R_{P}\right)$ ve risksiz faiz oranı $\left(R_{f}\right)$ arasındaki fark olarak ifade edilen portföy risk priminin portföyün standart sapmasına bölünmesiyle hesaplanan portföy performans ölçüm oranıdır. Bu oran Denklem (4)'te verilen formülle ifade edilmektedir (Sharpe, 1994: 3; Bodie, Kane ve Marcus, 2002: 919):

$$
\mathrm{SR}=\mathrm{S}_{\mathrm{P}}=\frac{\mathrm{R}_{\mathrm{P}}}{\sigma_{\mathrm{P}}}=\frac{E\left(\mathrm{r}_{\mathrm{P}}\right)-\mathrm{R}_{\mathrm{f}}}{\sigma_{\mathrm{p}}}
$$

Performans ölçüm tekniklerinden Sharpe ölçütü standart sapmayı, Treynor ve Jensen ölçütleri ise sistematik riski esas alır (Kaya ve Kocadağl1, 2012: 23). Bu çalışmada bunlardan yalnızca Sharpe oranı dikkate alınmıştır. Sharpe oranının belirlenmesinde kullanılan risksiz faiz oranı 18,77 olarak hesaplanmıştır.

Portföylerin 2018 Yılına ilişkin elde edilen sonuçları Tablo 4.'te verilmektedir.

Tablo 4: Portföylerin 2018 Yılına Ait OVM Sonuçları

\begin{tabular}{cccccc}
\hline Portföy & Hedeflenen Getiri & Varyans (Risk) & S. Sapma & Sharpe Oranı & Değişim Katsayısı \\
\hline $\mathbf{1}$ & 0,010 & 0,001 & 0,023 & 0,354 & 2,292 \\
\hline $\mathbf{2}$ & 0,015 & 0,001 & 0,024 & 0,542 & 1,613 \\
\hline $\mathbf{3}$ & 0,017 & 0,001 & 0,025 & 0,609 & 1,461 \\
\hline $\mathbf{4}$ & 0,020 & 0,001 & 0,026 & 0,699 & 1,296 \\
\hline $\mathbf{5}$ & 0,024 & 0,001 & 0,028 & 0,803 & 1,148 \\
\hline $\mathbf{6}$ & 0,026 & 0,001 & 0,028 & 0,847 & 1,095 \\
\hline $\mathbf{7}$ & 0,028 & 0,001 & 0,030 & 0,883 & 1,056 \\
\hline $\mathbf{8}$ & 0,030 & 0,001 & 0,031 & 0,911 & 1,029 \\
\hline $\mathbf{9}$ & 0,032 & 0,001 & 0,032 & 0,933 & 1,009 \\
\hline $\mathbf{1 0}$ & 0,035 & 0,001 & 0,035 & 0,955 & 0,991 \\
\hline $\mathbf{1 1}$ & 0,038 & 0,001 & 0,037 & 0,966 & 0,984 \\
\hline $\mathbf{1 2}$ & 0,040 & 0,002 & 0,039 & 0,970 & 0,983 \\
\hline $\mathbf{1 3}$ & 0,042 & 0,002 & 0,041 & 0,972 & 0,982 \\
\hline $\mathbf{1 4}$ & 0,045 & 0,002 & 0,044 & 0,973 & 0,985 \\
\hline $\mathbf{1 5}$ & 0,047 & 0,002 & 0,046 & 0,972 & 0,987 \\
\hline $\mathbf{1 6}$ & 0,050 & 0,002 & 0,050 & 0,969 & 0,993 \\
\hline $\mathbf{1 7}$ & 0,052 & 0,003 & 0,052 & 0,966 & 0,998 \\
\hline $\mathbf{1 8}$ & 0,054 & 0,003 & 0,054 & 0,962 & 1,004 \\
\hline $\mathbf{1 9}$ & 0,055 & 0,003 & 0,056 & 0,954 & 1,012 \\
\hline $\mathbf{2 0}$ & 0,056 & 0,003 & 0,058 & 0,928 & 1,041 \\
\hline $\mathbf{1 0}$ & & & & \\
\hline
\end{tabular}

Elde edilen sonuçlara göre optimum portföy 0,973 Sharpe oranına ve 0,985 Değişim Katsayısına sahip 14 numaralı portföydür. Bu portföyün hedeflenen getiri düzeyi $\% 4,5$ risk düzeyi ise $\% 0,02$ olarak karşımıza çıkmaktadır. 5 adet hisse senedinden oluşan bu portföyde 
yatırım yapılması önerilen hisse senetleri ve oranlar; ASELS $(0,64)$ ENKAI $(0,05)$ OTKAR $(0,05)$ PNSUT $(0,20)$ VESTL $(0,06)$ olarak siralanabilir.

2018 y1l için farklı hedeflenen getiri ve varyans seviyelerinde oluşturulan portföyler Şekil 1'de verilen etkin sınır eğrisinde gösterilmişstir.

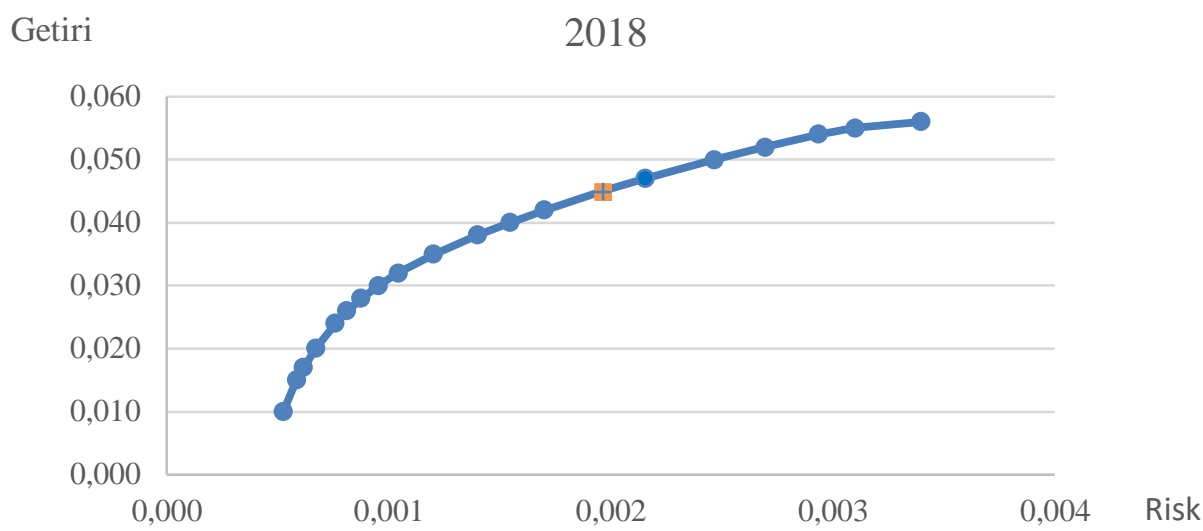

Şekil 1: 2018 Yılına Ait Etkin Sınır Eğrisi

Etkin sınır eğrisine göre yatırımcılar rasyonel olmaları durumunda $\% 1$ ile $\% 5,6$ getiri karşıllı̆ında \%0,01 ile \%0,3'lik bir riske de katlanmak durumunda kalacaktır.

\subsection{9-2017 Yılları İçin Ortalama Varyans Modeli Sonuçları}

Farklı hedeflenen aylık getiri ve risk oranlarına göre elde edilen sharpe oranları ve değişim katsayısı değerleri Tablo 5'te verilmektedir.

Tablo 5: Ortalama Varyans Modeline Göre Oluşturulan Optimum Portföyler

\begin{tabular}{cccccc}
\hline Yıllar & Getiri & Varyans & S. Sapma & Sharpe Oranı & Değişim Katsayısı \\
\hline $\mathbf{2 0 0 9}$ & 0,083 & 0,000 & 0,021 & 3,885 & 0,254 \\
\hline $\mathbf{2 0 1 0}$ & 0,057 & 0,001 & 0,036 & 1,547 & 0,638 \\
\hline $\mathbf{2 0 1 1}$ & 0,038 & 0,007 & 0,081 & 0,457 & 2,140 \\
\hline $\mathbf{2 0 1 2}$ & 0,044 & 0,001 & 0,028 & 1,556 & 0,631 \\
\hline $\mathbf{2 0 1 3}$ & 0,035 & 0,001 & 0,023 & 1,460 & 0,667 \\
\hline $\mathbf{2 0 1 4}$ & 0,035 & 0,001 & 0,027 & 1,287 & 0,757 \\
\hline $\mathbf{2 0 1 5}$ & 0,025 & 0,001 & 0,025 & 0,954 & 1,008 \\
\hline $\mathbf{2 0 1 6}$ & 0,017 & 0,000 & 0,005 & 3,251 & 0,290 \\
\hline $\mathbf{2 0 1 7}$ & 0,059 & 0,001 & 0,031 & 1,870 & 0,524 \\
\hline $\mathbf{2 0 1 8}$ & 0,045 & 0,002 & 0,044 & 0,973 & 0,985 \\
\hline
\end{tabular}

Elde edilen sonuçlara göre; 2009 ve 2016 yılları için en yüksek Sharpe oranı ile en düşük değişim katsayısı değerleri elde edilmiştir. 2009-2017 yılları için farklı hedeflenen getiri ve 
varyans seviyelerinde oluşturulan portföyler Şekil 2'de verilen etkin sınır eğrilerinde gösterilmiştir.
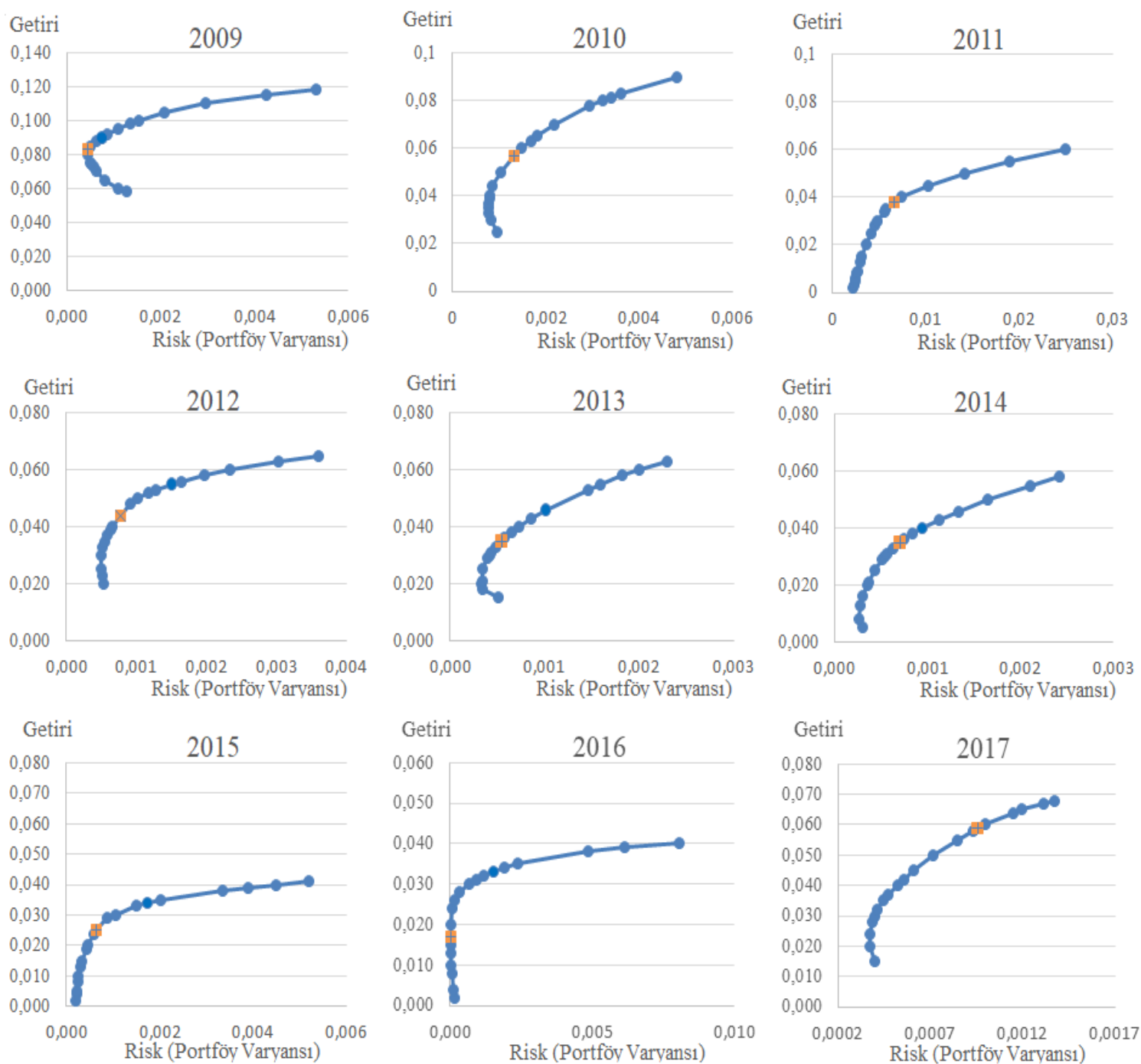

Şekil 2: 2009-2017 Yıllarına Ait Etkin Sınır Eğrileri

Etkin Sınır eğrilerinin grafikleri incelendiğinde her bir y1lda grafiklerin farklılaştığ1 değişik açılarda eğimlerin oluştuğu gözlenmektedir. 2009 ve 2016 yıllarında en yüksek sharpe oranları ve en düşük değişim katsayısı elde edilmiştir. Grafiklerde 0,001 risk düzeyi dikkate alındığında en yüksek getirinin 2009 yılında elde edildiği görülmektedir. 2017 yılı için de 0,001 risk düzeyi için getiri göreceli olarak yüksek değer almaktadır. Benzer şekilde 0,06 getiri için 2009, 2010 ve 2017 y1lları için 0,001 risk oluşurken diğer yıllarda daha yüksek risk seviyesi ile karşılaşılmıştır.

Her bir yıl için yatırım yapacak bir yatırımcının portföyüne hangi hisse senedinden ne oranda alması gerektiği hesaplanmıştır. Hesaplanan yatırım pay değerleri ve bu portföyde yatırım yapılması önerilen hisse senetleri Tablo 6'da verilmektedir. 
Tablo 6: OVM Göre Yatırım Yapılan Hisse Senetleri

\begin{tabular}{|c|c|c|}
\hline Yillar & Hisse Senetleri & Sayı \\
\hline 2009 & AKSA $(0,44)$ CCOLA $(0,35)$ DGGYO $(0,09) \operatorname{IZOCM}(0,12)$ & 4 \\
\hline 2010 & AGHOL $(0,22)$ DGGYO $(0,11)$ GLYHO $(0,29)$ PETUN $(0,10)$ SISE $(0,27)$ & 5 \\
\hline 2011 & SISE $(0,24)$ TOASO $(0,17)$ TTKOM $(0,59)$ & 3 \\
\hline 2012 & $\begin{array}{c}\text { ARCLK }(0,26) \text { DGGYO }(0,32) \text { EREGL }(0,04) \text { IZOCM }(0,05) \text { MGROS }(0,07) \text { TUPRS } \\
(0,11) \text { TTKOM }(0,02) \text { TTRAK }(0,13)\end{array}$ & 8 \\
\hline 2013 & $\begin{array}{l}\text { AGHOL }(0,25) \text { ARCLK }(0,01) \text { EREGL }(0,04) \operatorname{HURGZ}(0,16) \text { LOGO }(0,22) \text { TRCAS } \\
(0,14) \text { TTRAK }(0,18)\end{array}$ & 7 \\
\hline 2014 & $\begin{array}{c}\text { GLYHO }(0,12) \text { IHEVA }(0,21) \text { TATGD }(0,02) \text { TRCAS }(0,14) \text { TTKOM }(0,31) \text { TTRAK } \\
(0,13) \text { VESTL }(0,06)\end{array}$ & 7 \\
\hline 2015 & ASELS $(0,09)$ AYGAZ $(0,18)$ CCOLA $(0,13)$ MGROS $(0,08)$ TRCAS $(0,52)$ & 5 \\
\hline 2016 & $\begin{array}{c}\text { AYGAZ }(0,10) \text { CCOLA }(0,17) \text { LOGO }(0,21) \text { OTKAR }(0,03) \text { PETUN }(0,12) \text { PNSUT } \\
(0,24) \text { TATGD }(0,06) \text { TRCAS }(0,05) \text { TTKOM }(0,02)\end{array}$ & 8 \\
\hline 2017 & $\begin{array}{l}\text { AGHOL }(0,01) \text { ASELS }(0,30) \text { CCOLA }(0,08) \text { IHEVA }(0,10) \text { MGROS }(0,10) \text { PNSUT } \\
(0,39) \text { TUPRS }(0,02)\end{array}$ & 7 \\
\hline 2018 & ASELS $(0,64)$ ENKAI $(0,05)$ OTKAR $(0,05) \operatorname{PNSUT}(0,20) \operatorname{VESTL}(0,06)$ & 5 \\
\hline
\end{tabular}

Elde edilen sonuçlara göre; her yıl için oluşturulan optimum portföylerde en düşük 3 en çok 8 hisse senedine yatırım önerilmektedir. Ortalama değer yaklaşık olarak 6 hisse senedidir. Tüm yıllar dikkate alındığında toplam olarak en yüksek oranda yatırımı önerilen hisse senetleri ASELS, TTKOM, TRCAS, PNSUT, CCOLA, DGGYO, SISE, AGHOL, TTRAK, AKSA sıralamasını oluşturmuş̧tur.

\subsection{OVM ile En Yüksek Getirili 6 Hisse Senedi (EYG6HS) Kriterinin Karșılaștırması}

Çalışmanın uygulama kısmına son olarak, 2009-2018 yılları arasında en yüksek getiriye sahip 6 hisse senedi seçilerek basit çeşitlendirme mantığıyla oluşturulan portföylerin, Excel ortamında risk-getiri hesaplamas1 yapılarak Sharpe performans kriteri ve farklı yatırımların mukayesesinde uygun bir risk ölçütü özelliği taşımasından dolayı değişim katsayısı karşılaştırma kriterleri olarak değerlendirilmiştir. 6 hisse senedi seçilmesinin nedeni OVM modelinde y1llara ilişkin portföydeki hisse senedi ortalamasının 6'ya yakın olması ve bu değerin literatürde de önerilmesidir (Tosun ve Oruç, 2010). Her bir y1l için hisse senetlerinin ortalama getirisine göre belirlenen ve portföy içerisinde eşit ağırlıklı olarak yatırım yapılan, en yüksek getirili 6 hisse senedinden oluşan portföyler aşağıdaki tabloda gösterilmiştir. 
Tablo 7: En Yüksek Getirili 6 Hisse Senedinden Oluşan Portföyler

\begin{tabular}{cccccc}
\hline Yıl & Hisse Senetleri & $\begin{array}{c}\text { Portföy } \\
\text { Getirisi }\end{array}$ & $\begin{array}{c}\text { Portföy } \\
\text { S.Sapma }\end{array}$ & $\begin{array}{c}\text { Sharpe } \\
\text { Oranı }\end{array}$ & $\begin{array}{c}\text { Değ. } \\
\text { Kats. }\end{array}$ \\
\hline $\mathbf{2 0 0 9}$ & ZZOCM, AYGAZ, PNSUT,PRKME,TATGD,TAVHL & 0,126 & 0,199 & 0,626 & 1,583 \\
\hline $\mathbf{2 0 1 0}$ & GLYHO,PETUN,TTKOM,CCOLA,AKSA,EREGL & 0,073 & 0,130 & 0,558 & 1,775 \\
\hline $\mathbf{2 0 1 1}$ & SISE,AKSA,TUPRS,VESTL,TOASO,TTKOM & 0,042 & 0,155 & 0,267 & 3,668 \\
\hline $\mathbf{2 0 1 2}$ & GLYHO,TATGD,TUPRS,AYGAZ,IZOCM,CCOLA & 0,064 & 0,104 & 0,609 & 1,623 \\
\hline $\mathbf{2 0 1 3}$ & IHEVA,TATGD,CCOLA, ASELS, VESTL, EREGL & 0,334 & 1,282 & 0,260 & 3,838 \\
\hline $\mathbf{2 0 1 4}$ & TATGD, IHEVA, IZOCM, GLYHO, VESTL, IHLAS & 0,062 & 0,168 & 0,365 & 2,701 \\
\hline $\mathbf{2 0 1 5}$ & TATGD, AKSA, CCOLA,TOASO,TRCAS,PINSU & 0,038 & 0,121 & 0,309 & 3,159 \\
\hline $\mathbf{2 0 1 6}$ & ENKAI,TOASO,OTKAR,IHEVA,TATGD,CCOLA & 0,033 & 0,126 & 0,255 & 3,806 \\
\hline $\mathbf{2 0 1 7}$ & CCOLA,MGROS,PNSUT,IHEVA,PETUN,PRKME & 0,069 & 0,129 & 0,523 & 1,880 \\
\hline $\mathbf{2 0 1 8}$ & ASELS,ENKAI,IHEVA,OTKAR,VESTL,AEFES & 0,025 & 0,144 & 0,160 & 5,787 \\
\hline
\end{tabular}

Elde edilen sonuçlara göre; En yüksek Sharpe oranı ve en düşük değişim katsayısı değerleri 2009, 2010 ve 2017 yılları için gerçekleşmiştir.

Kıyaslama amacıyla, Ortalama Varyans Modeline göre oluşturulan optimum portföylerin Sharpe oranları ve değişim katsayılarının, en yüksek getirili 6 hisse senedinden oluşan portföylerin Sharpe oranları ve değişim katsayıları ile karşılaştırması yapılmıştır.

Elde edilen sonuçlar, Ortalama Varyans yöntemi ile oluşturulan portföylerin Sharpe oranlarının daha yüksek ve değişim katsayılarının daha düşük olduğunu göstermektedir. Böylece bir birim riske karşıllk en yüksek getiri bu yöntemle sağlanmış olup, diğer bir ifadeyle daha az riske ve daha yüksek performansa sahip portföyler OVM ile elde edilmiştir.

Kıyaslama yapılırken yil sayısının 10 yıl ile sinırlı olmasından dolay1 parametrik olmayan hipotez testlerinden Mann Whitney-U Testi (IBM SPSS) gerçekleştirilmiştir. Sharpe oranı için ele alınan hipotezler şu şekildedir: sahiptir.

Ho: OVM ile elde edilen portföylerin Sharpe oranları EYG6HS ile benzer dağılıma

$\mathrm{H}_{1}$ : OVM ile elde edilen portföylerin Sharpe oranları EYG6HS'den büyük olma eğilimindedir.

Değişim Katsayısı için ele alınan hipotezler ise şu şekildedir: sahiptir.

Ho: OVM ile elde edilen portföylerin değişim katsayıları EYG6HS ile benzer dağılıma

$\mathrm{H}_{1}$ : OVM ile elde edilen portföylerin değişim katsayıları EYG6HS'den küçük olma eğilimindedir.

Mann-Whitney U testi sonucuna göre; Sharpe oranı ve değişim katsayısı için (Exact Sig (1 tailed) 0,001 olarak elde edildiğinden yokluk hipotezi reddedilmiştir. Hipotez testi sonuçları aşağıda verilen tabloda sunulmaktadır. 
Tablo 8: Mann-Whitney U Testi

\begin{tabular}{ccc}
\hline & Sharpe Oranı & Değişim Katsayısı \\
\hline Mann-Whitney U & 4 & 4 \\
\hline Wilcoxon W & 59 & 59 \\
\hline $\mathbf{Z}$ & $-3,477$ & $-3,477$ \\
\hline Asymp. Sig. (2-tailed) & 0,001 & 0,001 \\
\hline Exact Sig. [2*(1-tailed Sig.)] &, $000 \mathrm{~b}$ &, $000 \mathrm{~b}$ \\
\hline
\end{tabular}

- OVM ile elde edilen portföylerin Sharpe oranlarının EYG6HS'den büyük olma eğiliminde oldukları söylenebilir.

- OVM ile elde edilen portföylerin değişim katsayılarının EYG6HS'den küçük olma eğiliminde oldukları söylenebilir.

Elde edilen verilerin yıllara göre değişiminin izlenebilmesi amacıyla grafik görünümleri de dikkate alınmıştır. Elde edilen grafikler Şekil 3 ve Şekil 4'te verilmektedir.

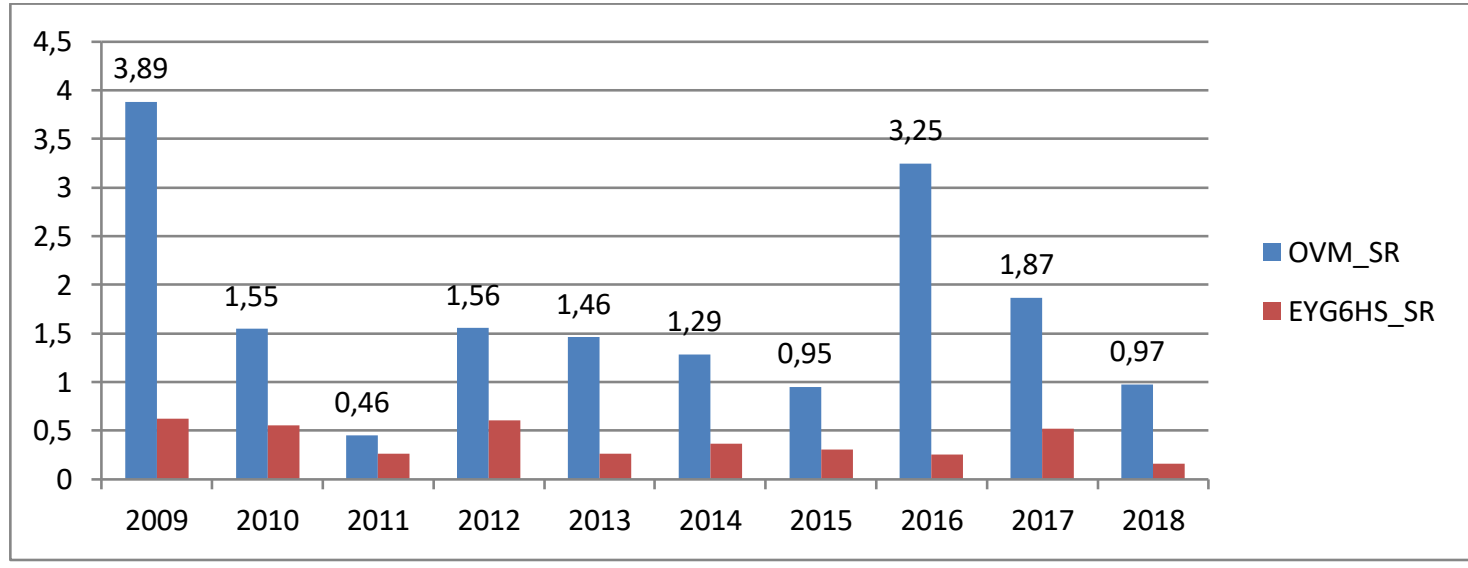

Şekil 3: Sharpe Oranları

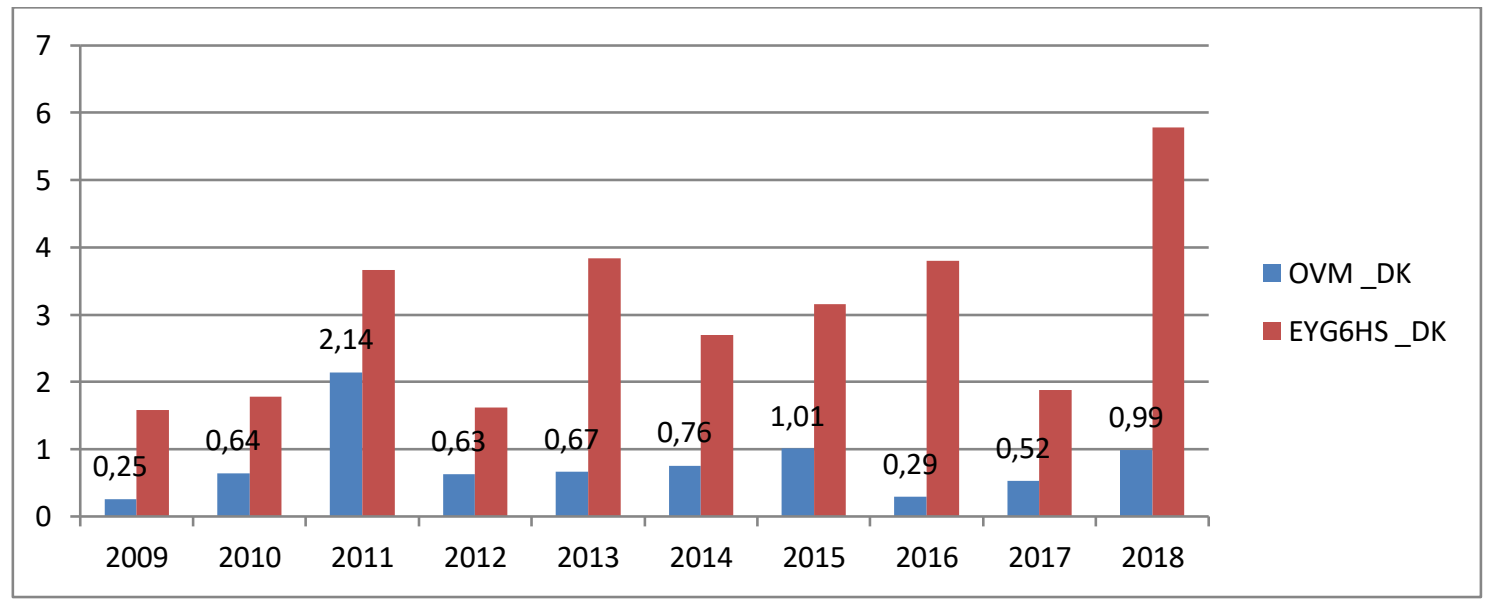

Şekil 4: Değişim Katsayıları 
Şekil 3 ve Şekil 4'ten de anlaşılacağı üzere yıllar itibariyle Ortalama Varyans Modeline göre oluşturulan optimum portföylerin her bir yıl için Sharpe oranı yüksek iken değişim katsayıları düşüktür. Bu durum değişim katsayısı düşük olan portföylerin beklenen getiri riskinin diğer portföylerden daha düşük olacağı anlamına gelmektedir. Birim getiri başına değişkenliğin daha düşük olması Ortalama Varyans Modelinin portföy optimizasyonu amaciyla kullanıma uygunluğunu desteklemektedir. OVM için Sharpe oranının en yüksek olduğu yıllar 2009 ve 2016 yıllarıdır. 2011 yılında Sharpe oranı en düşük değeri alırken değişim katsayısı en yüksek değeri almıştır.

\section{SONUÇ}

Bireyler belli bir birikime sahip olduklarında paralarına değer katmak amacıyla farklı yatırım araçlarına yatııı yapmak isterler. Yüksek getiri hedefleyen bir yatırımcı yüksek bir risk oranı ile karşı karşıya kalacaktır. Benzer biçimde yatırımcı daha düşük bir getiri hedefliyorsa katlanması gereken risk oranı da daha düşük olacaktır. Böylece yatırımcının risk alabilme düzeyi ya da hedeflediği getiri düzeyine göre farklı portföyler oluşturulabilir. Ancak hangi yatırım aracına yatırım yapılması gerektiğine karar vermek zorlu bir süreçtir. Bu durum çeşitli menkul kıymetlerden oluşan sepet olarak ifade edilen portföy kavramını ortaya çıkarmıştır. Yatırımcı, hangi menkul kıymetlerin hangi oranda portföy içerisine dahil edileceği sorusuna cevap bulmak istemektedir. Bu kararın alınmasında; daha iyi kurumsal yönetimi temsil eden BİST Kurumsal Yönetim Endeksi'nde yer alan şirketler avantajlı durumdadır ve güveni artıran ilkeleri benimsedikleri için uygun bir yapıya sahiptirler. Kurumsal Yönetim Endeksinde tek bir menkul kıymet yerine, birden fazla menkul kıymetin portföy içerisine dahil edilerek çeşitlendirilip riskin minimize edilmesi için de Markovitz Ortalama Varyans Modeli uygun bir model olarak karşımıza çıkmaktadır.

Bu çalışmada 2009-2018 dönemleri itibariyle yatırımcının risk-getiri kriterlerine göre oluşturulan portföyler arasından en uygun portföy seçimini yapabilmek için portföyün başarı düzeyinin tespit edilmesinde kullanılan Sharpe performans ölçütü ve değişim katsayısı esas alınmış ve her yıl için Sharpe oranı en yüksek, değişim katsayısı en düşük olan portföylerin yatırımcı açısından optimal portföy olduğu sonucuna varılmıştır. Çalışmada analizi yapılan OVM'nin optimizasyon işlemi için uygun çözümler sunabilmesi, yatırımcıların karar vermeleri açısından kullanışlı bir model olduğunu göstermektedir. Çalışmada her yıl için toplam 20 portföy oluşturulmuş ve bu portföylerin oluşturduğu sınır etkin sınır olarak ifade edilmiştir.

OVM'ye göre oluşturulan optimum portföylere ilaveten her yıl için oluşturulan en yüksek getirili 6 adet hisse senedi içeren portföyler uygulamaya dahil edilip bu portföylerin performansları tespit edilmiştir. İlgili yıllarda (2009-2018) en yüksek getiri sağlayan 6 hisse senedinden oluşan portföylerin Sharpe oranları ve birim getiri başına değişkenliği gösteren değişim katsayıları kıyaslandığında OVM için elde edilen değerler, en yüksek getiri sağlayan 6 hisse senedinden oluşan portföylerin sonuçlarından daha uygun çıkmıştır. OVM kapsamında oluşturulan portföylerin Sharpe oranlarının daha yüksek değişim katsayılarının daha düşük olduğu saptanmıştır.

Yöntemlerin sonuçlarının kıyaslanabilmesi için aralarındaki farklın anlamlı olup olmadığ 1 hipotez testi ile sınanmıştır. Elde edilen değerlerin yıl sayısının 10 yıl ile sınırlı olmasından dolayı parametrik olmayan hipotez testlerinden Mann Whitney-U Testi gerçekleştirilmiştir. Hipotez testi sonuçlarına göre; OVM ile elde edilen portföylerin sharpe oranları EYG6HS'den büyük olma eğilimindedir. Ayrıca; OVM ile elde edilen portföylerin değişim katsayılarının EYG6HS'den küçük olma eğiliminde oldukları söylenebilir.

Sonuç olarak yapılan çalışmada, BIST Kurumsal Yönetim Endeksine kote edilmiş olup verilerini temin edebildiğimiz firmalara ait hisse senetlerinden oluşan, yatırımcının hedeflediği 
getiri düzeyindeki minimum riskli portföyün elde edilmesi ve buna bağlı olarak fayda maksimizasyonunun sağlanması amaçlanmış ve uygulanan yöntemin optimizasyon açısından anlamlı ve rasyonel sonuçlar verdiği gözlemlenerek amaçlanan sonuçlara ulaşılmıştır. Benzer çalışmalar ayrıca farklı dönemler için farklı endekslere uygulanabilir. Ayrıca; aylık veriler yerine günlük verilerin kullanılması da etkili sonuçlar sunabilir.

\section{KAYNAKÇA}

Abay, R. (2013). Markowitz karesel programlama ile portföy seçimi: İMKB-30 endeksinde riskli portföylerin seçimi. Çukurova Üniversitesi Sosyal Bilimler Enstitüsü Dergisi, C. 22, S.2: 175-194.

Adıgüzel, M. B. (2019). Parçacık sürü optimizasyonu ile portföy optimizasyonu: Borsa İstanbul ulaştırma sektörü hisseleri üzerine bir uygulama. Journal Of Yaşar University, 14, 126-136.

Aksoy, E. E. (2014). Uluslarası portföy yönetimi. Ankara: Detay Yayıncılık.

Aksu, M., ve Aytekin, S. (2015). Kurumsal yönetim ilkelerine uyum notu ile hisse senedi getirisi ilişkisi: BIST kurumsal yönetim endeksi (XKURY) üzerine bir uygulama. Gümüşhane Üniversitesi Sosyal Bilimler Enstitüsü Elektronik Dergisi, C.6, N.13: 202-219.

Alagöz, A ve Kutlu, M. (2012). Parçacık sürü optimizasyonu yaklaşımı ile emtia piyasasında portföy optimizasyonu. Sosyal Ekonomik Araştırmalar Dergisi, C.12, S. 23: 35-50.

Altaylıgil, B. (2008). Portföy seçimi için ortalama-varyans-çarpıklık modeli. İstanbul Üniversitesi Iş̧letme Fakültesi Dergisi, C.37., S.2: 65-78.

Atan, M. (2005). Karesel programlama ile portföy optimizasyonu. VII. Ulusal Ekonometri Ve İstatistik Sempozyumu, Mayis, 26-27.

Ayaydın, H. (2013). Türkiye'deki emeklilik yatırım fonlarının performanslarının analizi. Çukurova Üniversitesi Sosyal Bilimler Enstitüsü Dergisi, C. 22, S.2: 59-80.

Aygören, H. ve Akyer, H. (2013). Etkin portföylerin belirlenmesinde veri aralı̆̆1, hisse senedi sayısı ve risk düzeyi faktörlerinin etkisi. Uluslararası Alanya İşletme Fakültesi Dergisi, C.5, S.2: 9-17.

Başar G. P. (2019). Optimum portföy oluşturma ve BIST’te bir uygulama, Balıkesir Üniversitesi, Sosyal Bilimler Enstitüsü, İşletme ABD. Yayımlanmamış Yüksek Lisans Tezi.133s.

Bayramoğlu, M. F., ve Yayalar, N. (2017). Portföy seçiminde toplam riski temel alan portföy performans ölçütlerinin değerlendirilmesi. Abant İzzet Baysal Üniversitesi Sosyal Bilimler Enstitüsü Dergisi, C. 17, S.1: 1-28.

Birgili, E., ve Tuna, G. (2010). Markowitz ve tek endeks modellerinin uygulanmas1: İMKB 30 endeksi üzerinde karşılaştırmalı analiz. Süleyman Demirel Üniversitesi İktisadi Ve İdari Bilimler Fakültesi Dergisi, C. 15, S.3: 1-18.

Bodie, Z. Kane, A., \& Marcus, A. J. (2002). Investments, McGraw-Hill/Irwin.

Brodie, J., Daubechies, I., De Mol, C., Giannone, D., \& Loris, I. (2009). Sparse and stable Markowitz portfolios. Proceedings of the National Academy of Sciences, V. 106 N.30: 12267-12272.

Cihangir, M.; Karaçizmeli G., A. \& Sabuncu, İ. (2008). Optimal portföy seçiminde Konno-Yamazaki modeli yaklaşımı ve İMKB mali sektör hisse senetlerine uygulanması. Gazi Üniversitesi İktisadi ve İdari Bilimler Fakültesi Dergisi, N. 3: 125-142.

Çalışkan, T. (2011). Black-Litterman ve Markowitz ortalama varyans modeliyle oluşturulan portföylerin performanslarının ölçülmesi. Yönetim ve Ekonomi Araştırmaları Dergisi. C 9, S 15 : 101-105.

Doğrusoy M. (2014). Kurumsal yönetim ilkelerine uyum derecelendirmesinde not güncellemeleri yapıldı, Kurumsal Yönetim, S.24: 1-56.

Doğukanlı H., ve Borak M. (2018). Portföy yönetimi. Karahan Kitabevi.

Elton, E. J., \& Gruber, M. J. (1997). Modern portfolio theory, 1950 to date. Journal of Banking \& Finance, V.21, N. (11-12): 1743-1759.

Finnet, Financial Information News Network https:/www.finnet.com.tr/FinnetStore/tr/ Erişim Tarihi: 01 Ağustos 2018-10 Ocak 2019.

IBM SPSS, Statistics for Windows, IBM Corp, Armonk, NY, USA. 
Jobson, J. D., \& Korkie, B. (1980). Estimation for Markowitz efficient portfolios. Journal of the American Statistical Association, V. 75, N.371: 544-554.

Kandemir, E., ve Aytekin, S. (2017). Optimum portföy seçimi ve BIST'TE ampirik bir uygulama. Social Science Studies, C.5, S.8: 87-110.

Karan M. B. (2013). Yatırım analizi ve portföy yönetimi, 4. Bask1 Ankara: Gazi Kitabevi.

Kardiyen, F. (2007). Doğrusal programlama ile portföy optimizasyonu ve İMKB verilerine uygulanması üzerine bir çalışma. Atatürk Üniversitesi İktisadi Ve İdari Bilimler Dergisi, C.21, N.2: 15-28.

Kaya, C., ve Kocadağlı, O. (2012). Etkin sınır ve beta katsayı kısıtlı portföy seçim modeli üzerine bir uygulama. İstanbul Ticaret Üniversitesi Fen Bilimleri Dergisi, S.22: 19-35.

Kocadağlı, O., \& Cinemre, N. (2010). Portföy optimizasyonunda SVFM ile bulanık doğrusal olmayan model yaklaşımı. Istanbul University Journal Of The School Of Business Administration, C.39, S.2: 359-369.

Küçükkocaoğlu, G. (2002). Optimal portföyün seçimi ve İMKB Ulusal-30 endeksi üzerine bir uygulama. ActiveBankacllık ve Finans Dergisi, C.26: 74-91.

Markowitz, H. (1952). Portfolio selection. The Journal Of Finance, V. 7 N.1: 77-91.

Metaxiotis, K., \& Konstantinos L. (2012). Multiobjective evolutionary algorithms for portfolio management: a comprehensive literature review. Expert Systems with Applications, V. 39, N 14: 11685-11698.

Microsoft Excel, Microsoft Corporation, Redmond, WA.

Mokhtar, M., Shuib, A., \& Mohamad, D. (2014). Mathematical programming models for portfolio optimization problem: a review. International Journal Of Social, Management, Economics And Business Engineering, V. 8, N.2: 443-450.

Pringle Jr. S., \& VanOrden, M. A. (2009). Applying modern portfolio theory and the capital asset pricing model to Dod's information technology investments, Master Of Science In Information Technology Management, Unpublished Thesis. Naval Postgraduate School. p.57.

Sakarya, Ş. (2011). İMKB kurumsal yönetim endeksi kapsamındaki şirketlerin kurumsal yönetim derecelendirme notu ve hisse senedi getirileri arasındaki ilişkinin olay çalışması (event study) yöntemi ile analizi. Zonguldak Karaelmas University Journal Of Social Sciences, C.7, N.13.

Sharpe, W. F. (1994). The sharpe ratio. Journal Of Portfolio Management, V. 21, N.1: 49-58.

Steinbach, M. C. (2001). Markowitz revisited: Mean-variance models in financial portfolio analysis. SIAM review, . 43, N.1: 31-85.

TCMB www.tcmb.gov.tr/

$\mathrm{http} / / \mathrm{www} . t \mathrm{cmb}$.gov.tr/wps/wcm/connect/tr/tcmb+tr/main+menu/istatistiklerpiyasa+verileri/ihale+yontemi+ile+satila n+hazine+bonolari+ve+devlet+tahvilleri/ Erişim tarihi: 21 Kasım 2018.

Topal, Y., ve İlarslan, K. (2009). Portföy optimizasyonu bağlamında tanjant portföyleri: İMKB 30 işletmelerinden bir örnek. Afyon Kocatepe Üniversitesi İ.I.B.F. Dergisi, C.XI. S. I.: 219-247.

Tosun, Ö., ve Oruç, E. (2010). Portföy büyüklüğünün portföy riski üzerine etkileri: İMKB-30 üzerinde test edilmesi. Süleyman Demirel Üniversitesi İktisadi ve İdari Bilimler Fakültesi Dergisi, C.15, S.2: 479-413.

Uğurlu, M., Erdaş, M. L., \& Eroğlu, A.. (2016). Portföy yönetiminde sistematik olmayan riski azaltacak bir doğrusal programlama model önerisi. Çankırı Karatekin Üniversitesi İktisadi ve İdari Bilimler Fakültesi Dergisi, C. 6, S.1: $147-174$.

Ulucan, A. (2004). Portföy optimizasyonu: kuadratik programlama tabanlı modelleme. (1. Bask1). Ankara: Siyasal Kitabevi.

Ustaoğlu, E., ve Altay, E. (2017). Borsa İstanbul'da log-optimal portföy uygulaması. Uygulamalı Sosyal Bilimler Dergisi. C.1. S.1: 67-85.

Yavuz M., Sakarya Ş., \& Özdemir, N. (2015). Yapay sinir ağları ile risk-getiri tahmini ve portföy analizi. Ömer Halisdemir Üniversitesi İktisadi Ve İdari Bilimler Fakültesi Dergisi, C. 8, S.4: 87-107.

Zhang, Y. Li, X., \& Guo, S. (2018). Portfolio selection problems with Markowitz's mean-variance framework: a review of literature. Fuzzy Optimization And Decision Making, V. 17, N. 2: 125-158. 


\section{Extended Summary}

\section{Optimum Portfolio Creation: BIST Corporate Governance Index (XKURY) Application}

Portfolio optimization aims to achieve minimum risk and maximum return. For this purpose, a mathematical model is used to calculate the proportional distribution of financial assets to be included in the portfolio by taking certain constraints into account. Many portfolio management techniques have been developed to enable investors to make the right decision to reach the optimum portfolio. In this study, the mean-variance model (OVM) of Harry Markowitz, the founder of Modern Portfolio Theory was used. The purpose of this study is to create portfolios consisting of stocks of companies traded in BIST (Borsa Istanbul) Corporate Governance Index (XKURY) based on Markowitz's Average Variance model and to obtain optimal portfolio within these portfolios within the risk-return relationship by using Sharpe performance criterion and coefficient of change. In this study, it is concluded that companies that can achieve compliance with corporate governance principles should be examined especially for portfolio optimization on the assumption that they have competitive advantage and low risk levels. Taking into account the targeted returns between 2009 and 2018, effective boundary curves were drawn and Sharpe ratios and coefficients of variation were calculated. In addition, the performances of the portfolios formed by the inclusion of 6 stocks with the highest return among 34 stocks were measured (EYG6HS) and compared with the performances of the portfolios formed according to the Mean Variance Method.

The hypotheses discussed for the Sharpe ratio are as follows: EYG6HS.

HO: Sharpe ratios of portfolios obtained with OVM have similar distribution with

H1: Sharpe ratios of portfolios obtained with OVM tend to be greater than EYG6HS.

The hypothesis for the coefficient of variation is as follows: as EYG6HS.

HO: The coefficients of variation of portfolios obtained by OVM are similar distribution

H1: The coefficients of variation of portfolios obtained with OVM tend to be smaller than EYG6HS.

When the subject is considered theoretically; according to the average variance model, there are two basic principles based on maximizing the expected return with fixed variance and minimizing variance by keeping the expected return constant. In this way, it is ensured that an effective boundary curve which is suitable for making a selection consisting of portfolios based on the individual risk return preferences of the investor is provided.

The data in the study are BIST data. Monthly closing values of 34 stocks traded in BIST Corporate Governance Index between January-2009 and December-2018 were used as data set in the study. The data set consists of retrospective data of the companies included in the Corporate Governance Index as of August 2018. The available data was provided for the purpose of academic study from the Financial Information News Network (FINNET) Analysis Expert database. Another set of data used in the study is the risk-free interest rates needed to calculate the Sharpe rate. In the calculation of interest rates (EYG6HS), the average annual simple interest rates of the short-term government domestic debt securities issued by the CBRT (TCMB) for the related years were used.

In this study, 20 portfolios were created for each year according to the risk-return criteria of the investor as of 2009-2018 periods and the limit of these portfolios was defined as the effective limit. In order to select the most appropriate portfolio among the portfolios created, 
Sharpe performance criterion and coefficient of variation are used to determine the success level of the portfolio.

In addition to the optimum portfolios created in accordance with the OVM, the portfolios with the six highest-yielded stocks (EYG6HS) created for each year were included in the application and their performances were determined.

In order to compare the results of the methods, hypothesis testing was used to determine whether the difference between them was significant. Mann Whitney-U Test, which is one of the nonparametric hypothesis tests, was performed since the number of years obtained was limited to 10 years. According to hypothesis test results; Sharpe ratios of portfolios obtained with OVM tend to be greater than EYG6HS. Also; It can be said that the coefficient of variation of portfolios obtained with OVM tend to be less than EYG6HS.

The years in which the Sharpe ratio is highest for OVM are 2009 and 2016. In 2011, Sharpe ratio had the lowest value and the coefficient of variation had the highest value.

In this study, Sharpe performance criterion and coefficient of variation are used for determining the success level of the portfolio in order to make the most suitable portfolio selection among the portfolios formed according to the risk-return criteria of the investor as of 2009-2018 periods and the sharpe ratio is the lowest and the coefficient of variation is the lowest. It is concluded that the portfolios are the optimal portfolio for the investor. Sharpe ratios of portfolios created under OVM were found to have higher coefficients of variation lower than the highest yielded 6 stocks. The fact that OVM, which is analyzed in the study, provides suitable solutions for the optimization process shows that it is a useful model for investors to make decisions.

As a result of this study, it was aimed to obtain the minimum risky portfolio consisting of the shares of the companies listed in the BIST Corporate Governance Index at the level of return targeted by the investor and to achieve the profit maximization accordingly, and the results obtained were observed to be meaningful and rational in terms of optimization. Similar studies can also be applied to different indices for different periods. Also; using daily data instead of monthly data can also provide effective results. 